\title{
Anatomic Study and Assembled Navigation Template-Assisted Implantation for Anterograde Transpubic Screws
}

\author{
Chao Wu ( $\nabla$ flightiness@163.com ) \\ Danwei Shen \\ Zigong Fourth People's Hospital \\ Jiayan Deng \\ Zigong Fourth People's Hospital \\ Bofang Zeng \\ Zigong Fourth People's Hospital \\ Xiangyu Wang \\ Zigong Fourth People's Hospital \\ Hong Li \\ Zigong Fourth People's Hospital \\ Lian Xu \\ Zigong Fourth People's Hospital \\ Min Luo \\ Zigong Fourth People's Hospital
}

Zigong Fourth People's Hospital https://orcid.org/0000-0002-7215-1460

\section{Research Article}

Keywords: Pelvic fracture, Anatomy, Anterograde transpubic screw, Minimally invasive, 3D printing

Posted Date: December 16th, 2021

DOI: https://doi.org/10.21203/rs.3.rs-1157918/v1

License: @ (i) This work is licensed under a Creative Commons Attribution 4.0 International License. Read Full License 


\section{Abstract}

Objective: Research the anatomical parameters of the anterograde transpubic screw corridor and evaluate the safety of anterograde transpubic screw placement assisted by the assembled navigation template.

Methods: A total of 50 normal subjects, including 25 males and 25 females, underwent pelvic CT scanning in our hospital from

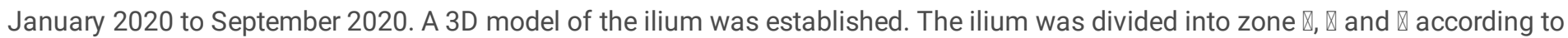
Nakatani classification. The anterograde transpubic screw channel completely passes through zone $₫$ and $\otimes$ to form corridor $A$. The anterograde screw channel completely passes through zone $\nabla, \nabla$ and $\nabla$ to form corridor $B$. The diameter and length of the inner circle, the distance from the center of the inner circle to the posterior superior and to the inferior iliac spine of corridor A and corridor B were measured, respectively. A total of 9 patients underwent anterograde transpubic screw and transverse sacroiliac screw placement assisted by the assembled navigation template in our hospital, including 5 males and 4 females, were retrospectively analyzed. Operative time, blood loss, incision length and fluoroscopy times were recorded. Grading score and Matta score were evaluated after surgery.

Results: In 50 normal subjects, the diameter of corridor A was $11.16 \pm 2.13 \mathrm{~mm}$, and that of corridor B was $8.54 \pm 1.52 \mathrm{~mm}$, and the difference between the two corridors was statistically significant $(P=0.000)$. The length of corridor $A$ was $86.39 \pm 9.35 \mathrm{~mm}$, and that of corridor $B$ was $117.05 \pm 5.91 \mathrm{~mm}$, with significant difference between the two corridors $(P=0.000)$. The surface distance from the screw entry point to the posterior superior iliac spine in corridor A was $109.31 \pm 11.06 \mathrm{~mm}$, and that in corridor B was $127.86 \pm 8.23 \mathrm{~mm}$, the difference between the two corridors was statistically significant $(P=0.000)$. The surface distance from the screw entry point to the posterior inferior iliac spine in corridor $A$ was $91.16 \pm 10.34 \mathrm{~mm}$, and that in corridor $B$ was $106.92 \pm 7.91 \mathrm{~mm}$. The difference between the two corridors was statistically significant $(P=0.000)$. Nine patients successfully completed surgery, and a total of 18 sacroiliac transverse screws and 11 anterograde transpubic screws were inserted with the assistance of assembled navigation templates. The mean operation time of the 9 patients was $108.75 \pm 25.71 \mathrm{~min}$, the blood loss was $141.11 \pm 50.21 \mathrm{ml}$, the incision length was $14 \pm 4.62 \mathrm{~cm}$, and the intraoperative fluoroscopy was $17.89 \pm 4.01$ times. Matta scores were excellent in 5 patients and good in 4 patients. One of the anterograde transpubic screw was in Grade 1, and 10 were in Grade 0. One S1 screw was in Grade 1, and 8 S1 screws were in Grade 0. Nine S2 screws were in Grade 0.

Conclusions: Majority of the patients can accommodate anterograde transpubic screw s with diameter of $6.5 \mathrm{~mm}$. Anterograde transpubic screw placement assisted by an assembled navigation template is clinically feasible, and with low cortical breaches.

\section{Introduction}

Pelvic fractures often result in instability of the anterior or posterior ring [1-4]. To maintain the stability of the pelvis, the current treatment methods mostly involve simultaneous internal fixation [5]. For posterior pelvic ring fractures, sacroiliac screws have become a popular technique for many orthopedic surgeons because of their good biomechanical performance [6]. However, there are few anatomical and biomechanical studies on anterior ring instability, especially for pubic ramus fractures. Common anterior ring fixation techniques include plate fixation, anterior ring percutaneous fixation (Infix) and transpubic screw fixation [7]. Through mechanical experiments, researchers have confirmed that transpubic screws can maintain the stability of the anterior ring of the pelvis [8]. Based on its advantages of good mechanical stability and low trauma, transpubic screws are considered to be the best surgical method for pubic fracture [9]. An anatomic study of 260 transpubic screw corridors found that all males were able to accommodate the insertion of screws with a diameter of $6.5 \mathrm{~mm}$, while $15 \%$ of females were unable to accommodate the insertion of screws with a diameter of $6.5 \mathrm{~mm}$ [10-11]. Most men could even accommodate the insertion of a $7.3 \mathrm{~mm}$ diameter screw [12]. However, most of these studies were based on two-dimensional images of patients, which are not intuitive and accurate, and lack analysis of Asian populations and clinical application. At present, the clinical application is mostly seen in retrograde transpubic screws, which require changing the patient's position during surgery, increasing the risk of infection [13-14].

In this study, a method of rapid transpubic screw corridor extraction was developed; the cancellous corridor of transpubic screws was analyzed and measured through digital 3D modeling, and the anatomical conditions of transpubic screws in a population in Southwest China were determined. During surgery, the patient was placed in the standard prone position, assisted by an assembled navigation template, while the sacroiliac and transpubic screws were inserted. After surgery, the safety of the screws was evaluated based on cortex penetration. 
This study aimed to (i) explore a rapid method to obtain a transpubic screw corridor, (ii) evaluate the feasibility of transpubic screw placement, and (iii) assess the safety of the assembled navigation template for screw placement.

\section{Materials And Methods}

\section{Measures of anatomical conditions}

For the study, pelvic computed tomography (CT) datasets with a slice thickness of $0.625 \mathrm{~mm}$ were collected from our hospital between December 2019 and October 2020, and residual trauma and tumorous, inflammatory or high-grade degenerative alterations were excluded. Ultimately, 50 adults (including 25 males and 25 females) were included in the study. Informed patient consent for further research applications of image data was obtained.

The CT data were imported into Mimics 22.0 (Materialise, Leuven, Belgium). Based on the CT values of the bones, a pelvic mask was obtained (covering cancellous and cortical bones). The bilateral iliac crests were separated from the bone mask, and 3D models were

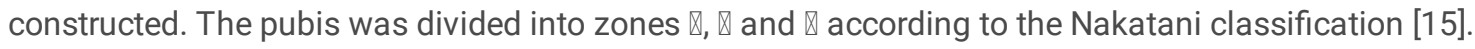

In transparent mode, by rotating the ilium to the appropriate position, corridor A (approximately an oval) was formed by pubis

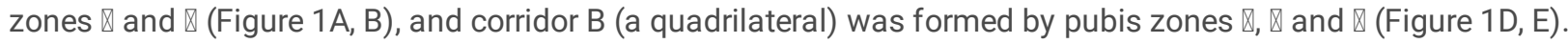

The diameter of the tangent circle and the length of the two corridors were measured. The distance along the iliac crest surface from the center of the tangent circle of the two channels to the posterior superior iliac spine and to the posterior inferior iliac spine was also measured (Figure 1C, F).

\section{Patients}

The inclusion criteria were as follows: definite reducible public fracture with zone $\nabla$ and $\nabla$ are associated with sacral fractures (Denis type $\mathbb{\nabla} / \mathbb{Q}$ ) or reducible sacroiliac dislocation, the superior ramus pubis screw channel can accommodate screws of at least $6.5 \mathrm{~mm}$ diameter, and tile classification B/C. The exclusion criteria were as follows: patients with severe systemic diseases and open pelvic fractures, fracture and sacroiliac dislocation cannot be closed reduction.

A total of 9 patients with fractures in the pubis in our hospital from January 2020 to September 2020 were enrolled in this research, including 5 males and 4 females. Their ages ranged from 21 to 65 years, and their average age was 47 years. Six of the patients were injured from traffic accidents, 3 of them were injured from falling, and the others were injured for other reasons. CT scans were performed on the pelvises of all patients before surgery (Table 1).

\section{Design of an assembled navigation template}

The 3D model of the patient's pelvis was constructed in mimics 22.0. Corridor A or B was determined according to the location of the fracture in the superior ramus of the pubis, and then a virtual screw with a diameter of $6.5 \mathrm{~mm}$ was inserted along corridor $A$ or B (Figure 2A). At the same time, sacroiliac screw diameters of $7.3 \mathrm{~mm}$ via S1 and S2 were inserted simultaneously according to Wu C's method [16]. Then, the pelvis and virtual screw were imported into 3-matic 14.0 (Materialise, Leuven, Belgium). The projection of the virtual screw to the surface of the iliac crest is used as the entry position, with the surface of the iliac bone covering the entry point. The posterior superior iliac spine and the posterior inferior iliac spine were then extracted and stretched outward $4 \mathrm{~mm}$ as the base of the navigation template. The base is designed with internal threaded holes in the direction of the virtual screw for assembly with the navigation pipe. The navigation pipe with thread at the bottom is designed along the direction of the virtual screw (Figure 2B, C). The navigation pipe is designed with a hole along the virtual screw that can accommodate the diameter of 2.6-mm K-wires. Finally, the navigation pipe was assembled with the base through a threaded structure (Figure 2D). Then, an assembled navigation template to assist simultaneous transpubic screw S1 and S2 screw placement was formed.

\section{Preoperative preparation}

The navigation template base, navigation pipes and pelvis were saved in STL format and imported into 3D printers (3DS, projet 3600) and (3D talk, FDM 460) (Figure 3A, B). The operative procedure was simulated based on the 3D-printed object, K-wires were inserted under the assistance of a navigation template, and the consistency with the preoperative design was evaluated (Figure 3C, D). The navigation template and pelvic model were hypothermically disinfected before surgery.

Page 3/12 
The operations were performed by the same surgeon with more than 10 years of experience. All patients were informed of the experimental design before the surgery and signed an informed consent form.

Under general anesthesia, the patient was placed in the standard prone position on a radiolucent operation table. First, traction reduction was performed for some patients, Reduction of fracture or dislocation was confirmed by intraoperative C-arm fluoroscopy. Second, posterior superior iliac spine and screw insertion points were located on the body surface. Third, the soft tissue of the posterior superior iliac spine was stripped, and the template base was inserted through the above incision and completely attached to the corresponding target spot (Figure 4A). Fourth, threaded navigation pipes were inserted through a small incision and assembled and fixed with the navigation template base in the wound (Figure 4B). Fifth, several K-wires $2.5 \mathrm{~cm}$ in diameter were drilled through navigation pipes (Figure 4C). Pelvic inlet, outlet and lateral sacral fluoroscopy images were obtained to confirm the positions of the Kwires (Figure 5A, B, C). Sixth, the navigation pipes were removed after the K-wire positions were confirmed (Figure 4D), and cannulated screws with diameters of $7.3 \mathrm{~mm}$ and $6.5 \mathrm{~mm}$ were screwed into the sacrum and pubis along the K-wires, respectively (Figure 4E). Finally, the K-wires and template base were removed (Figure 4F).

\section{Evaluation criteria}

\section{Anatomical parameters of anterograde transpubic screws}

The tangent circle diameter for corridor $\mathrm{A}$ or $\mathrm{B}$ was measured to evaluate whether a 6.5 -mm-diameter screw could be inserted into the pubic ramus. The length of corridor A or B was measured to evaluate the length of the transpubic screw. The surface distance from the screw entry point to the posterior superior iliac spine and to the posterior inferior iliac spine was measured as a reference for the covering area of the navigation template base.

\section{Operated information for patients}

Screw safety was assessed using the grading score [17]. The quality of the reduction was assessed by the Matta score [18].

\section{Statistical analysis}

All statistical analyses were performed in SPSS 19.0 (SPSS Inc., Chicago, IL, USA). Student's t-test was performed for the diameter of the corridors, the length of the corridor, and the surface distance from the screw entry point to the posterior superior iliac spine and inferior iliac spine. Descriptive statistics were performed on the general parameters and operative parameters of the patients. The confidence interval was set at $95 \%$, and $\mathrm{P}<0.05$ was regarded as a significant difference.

\section{Results}

\section{Anatomical measurement}

A total of 50 normal adults were enrolled in this study. The diameters were $11.16 \pm 2.13 \mathrm{~mm}$ for corridor $A$ and $8.54 \pm 1.52 \mathrm{~mm}$ for corridor $B$, and with a significant difference between the two corridors $(P=0.000)$, The lengths were $86.39 \pm 9.35 \mathrm{~mm}$ for corridor $A$ and $117.05 \pm 5.91 \mathrm{~mm}$ for corridor $B$, with a significant difference between the two corridors $(P=0.000)$. The surface distances from the screw entry point to the posterior superior iliac spine were $109.31 \pm 11.06 \mathrm{~mm}$ for corridor $A$ and $127.86 \pm 8.23 \mathrm{~mm}$ for corridor $B$, with a significant difference between the two corridors $(P=0.000)$. The surface distances from the screw entry point to the posterior inferior iliac spine were $91.16 \pm 10.34 \mathrm{~mm}$ for corridor $A$ and $106.92 \pm 7.91 \mathrm{~mm}$ for corridor $\mathrm{B}$, with a significant difference between the two corridors $(\mathrm{P}=0.000)$.

\section{Clinical indicators}

A total of 9 patients completed the surgery successfully, with 18 sacroiliac screws and 11 anterograde transpubic screws implanted under the assistance of assembled navigation templates (Figure 5D-I). There were no complications, such as vascular and nerve injury, and 1 patient developed superficial wound infection. After wound treatment and dressing changes, the wound healed. The 9 patients had an average surgical time of $108.75 \pm 25.71 \mathrm{~min}$, a blood loss of $141.11 \pm 50.21 \mathrm{ml}$, an incision length of $14 \pm 4.62 \mathrm{~cm}$, and a radiation of $17.89 \pm 4.01$ times. One anterograde transpubic screw was Grade 1, and 10 screws were Grade 0 . One S1 screw was 
Grade 1, and 8 S1 screws and 9 S2 screws were Grade 0 (Table 2). Five patients had excellent Matta scores, and 4 had good Matta scores.

\section{Discussion}

\section{Anatomical conditions of anterograde transpubic screws}

Retrograde transpubic screw fixation can provide stability of the anterior pelvis with fewer surgical exposures than plate fixation [1920]. There have been many studies on the anatomic measurement of retrograde transpubic screws, and taking reproductive structures as the marking point, the entry point of retrograde transpubic screws was located, which greatly reduced the difficulty of screw placement [21-23]. Zhang LH developed a navigation apparatus to assist with the placement of percutaneous retrograde transpubic screws to minimize trauma [24]. However, the reduction failure rate is up to $15 \%$ after percutaneous screw fixation for pubic ramus fractures, and failure is particularly common in elderly patients and females [25]. Peng $Y$ found that there are many variations between anterograde transpubic screws and retrograde transpubic screws at the entry point, and there is a larger screw insertion area for anterograde transpubic screws than for retrograde transpubic screws [26]. However, there are currently few clinical and anatomical studies on anterograde transpubic screws. In this study, we established a three-dimensional model of the pubis and quickly obtained the anterograde pubis ramus screw channel. The channels were classified according to the positions of different outlet points of the anterograde transpubic screws, and the anatomical parameters of different channels were obtained. In this study, corridor $A$ had an average diameter of $11.16 \pm 2.13 \mathrm{~mm}$, and corridor $B$ had an average diameter of $8.54 \pm 1.52 \mathrm{~mm}$. Cortical thickness was reduced by $1.77 \mathrm{~mm}$ [27], and it was confirmed that most Asian populations could accommodate a 6.5-mm screw.

\section{Advantages of anterograde transpubic screws}

Although the anterograde transpubic screw show a larger entry point area in the anatomical study [26], the lack of significant anatomical markers makes it very difficult to accurately place the anterograde transpubic screw. Therefore, there are few clinical applications of anterograde transpubic screws. In addition, expensive computer navigation or robotic navigation increases the cost of anterograde transpubic screw placement. In this study, based on the anatomical characteristics of the pubis, we used an assembled navigation template to assist in the placement of the anterograde transpubic screw, and there were only 2 screws in grade 1 and 27 screws in grade 0 . The advantages of assembled navigation template-assisted placement of the anterograde transpubic screw are as follows: First, the anterograde transpubic screw had more excellent fixation strength than a plate or a retrograde transpubic screw [2829]. Second, a minimally invasive screw fixation technique for pelvic fractures can significantly reduce trauma, with equivalent clinical results for unstable pelvic fractures [25,30]. In addition, the procedure is minimally invasive and has good fracture reduction according to the Matta score in this study. Third, simultaneous placement of sacroiliac screws and anterograde transpubic screws in a prone position can avoid intraoperative position changes, reducing the operation time and the risk of infection. In this study, the average operation time of 9 patients was only 108 minutes, and the procedures had a low infection rate [31]. Fourth, anterograde transpubic screw fixation can avoid many problems, such as large trauma due to anterior ring fixation and injury of the lateral femoral cutaneous nerve. Fifth, the assembled navigation template can significantly improve the safety of screw placement, and no screw penetrated the cortex more than $2 \mathrm{~mm}$ in our study.

\section{Surgical tips}

First, the base of the navigation template should cover important targets, such as the posterior superior iliac spine and the posterior inferior iliac spine. Second, the navigation template base will be warped if it is too long, therefore, the navigation template base should be shortened as much as possible while still covering important targets. The directions of the navigation pipes should not intersect to prevent interference between screws, and K-wire holes are designed based on the navigation template to strengthen the fixation between the navigation template and the iliac crest. Third, the entry point of the transpubic screw should be located on the body surface under fluoroscopy before surgery to reduce the tension of skin and soft tissue. Fourth, the soft tissue around the target should be thoroughly removed during the operation to ensure the tight attachment of the navigation template base. Fifth, it is recommended to perform pelvic inlet, outlet and lateral sacral fluoroscopy. Finally, navigation K-wires for sacroiliac screws are recommended to be inserted first to enhance the stability of the navigation template base, followed by navigation K-wires for transpubic screw insertion.

\section{Limitations}

Page 5/12 
A total of 50 normal persons were included in this study, and there was not enough diversity in the sample. The sample size will be expanded in the future to obtain more objective and accurate nail track parameters. In addition, once the intraoperative incision deviates from the screw entry point are located on the body surface, soft tissue tension will reduce the accuracy of the navigation wire, therefore, we are developing a metal mesh that can be attached to the skin for the positioning of the entry point.

\section{Conclusion}

This research demonstrates that the majority of patients can accommodate transpubic screws with a diameter of $6.5 \mathrm{~mm}$. Anterograde transpubic screw placement assisted by an assembled navigation template is clinically feasible, and with low cortical breaches.

\section{Abbreviations}

CT, computed tomography

\section{Declarations}

\section{Ethics approval and consent to participate}

This study was approved by the ethics committee of Zigong Fourth People's Hospital (No. 02, 2013). All patients signed the informed consents to participate in the study.

Informed consent was obtained from all individual participants included in the study

\section{Consent for publication}

The participant has consented to the submission of the case report to the journal.

Patients signed informed consent regarding publishing their data and photographs.

\section{Availability of data and materials}

The patients' data and software were authorized to our research.

\section{Competing interests}

The authors have no conflict of interest. This study was approved by the ethics committee of our hospital.

\section{Funding}

This study was supported by Sichuan Key Science and Technology Plan Project (21YYJC2898), Scientific research project of Sichuan Health Commission (20PJ274), Science and Technology Project of Sichuan Medical Association (S20010), Science and Technology Cooperation Project between Sichuan University and Zigong (2018CDZG-20).

\section{Authors' contributions}

Chao Wu was responsible for experiment design and paper review, Danwei Shen for data preprocessing, Jiayan Deng for data analysis and paper writing, Bofang Zeng, Xiangyu Wang, Hong Li, Lian Xu and Min Luo for clinical trials.

\section{Acknowledgements}

Thanks to the Zigong fourth people's hospital for providing the experimental equipment and site.

\section{References}


1. Zhang BF, Shang K, Wang PF, (2020) Comparison of posterior ring fixation with combined anterior and posterior ring fixation for the treatment of lateral compression type 2 pelvic fractures. Int Orthop, 44(6): p.1187-1193.

2. Küper MA, Trulson A, Stuby FM, Stöckle U (2019) Pelvic ring fractures in the elderly. EFORT Open Rev, 4(6): p.313-320.

3. Das S (2020) Comment on the article "Comparison of posterior ring fixation with combined anterior and posterior ring fixation for the treatment of lateral compression type 2 pelvic fractures". Int Orthop, 44(7): p.1445-1446.

4. Zhang BF, Zhuang Y (2020) Answer letter concerning "Comparison of posterior ring fixation with combined anterior and posterior ring fixation for the treatment of lateral compression type 2 pelvic fractures". Int Orthop, 44(7): p.1447-1448.

5. Shieh AK, Hayes CB, Shelton TJ, Chip Routt ML Jr, Eastman JG (2021) Low Superior Transpubic screw Failure Rate With Combined Anterior and Posterior Pelvic Ring Fixation. J Orthop Trauma, 35(4): p.175-180.

6. Zhao Y, Zhang S, Sun T (2013) Mechanical comparison between lengthened and short sacroiliac screws in sacral fracture fixation: a finite element analysis. Orthop Traumatol Surg Res, 99(5): p.601-606.

7. Vaidya R (2020) Fixation of Anterior Pelvic Ring Injuries. J Am Acad Orthop Surg, 28(13): p. e550-e551.

8. McLachlin S, Lesieur M, Stephen D, Kreder H, Whyne C (2018) Biomechanical analysis of anterior ring fixation of the ramus in type C pelvis fractures. Eur J Trauma Emerg Surg, 44(2): p.185-190.

9. Zhao Y, Ma Y, Zou D (2020) Biomechanical comparison of three minimally invasive fixations for unilateral pubic rami fractures. BMC Musculoskelet Disord, 21(1): p.594.

10. Ochs BG, Stuby FM, Ateschrang A, Stoeckle U, Gonser CE (2014) Retrograde lag screw placement in anterior acetabular column with regard to the anterior pelvic plane and midsagittal plane - virtual mapping of 260 three-dimensional hemipelvises for quantitative anatomic analysis. Injury, 45(10): p.1590-1598.

11. Chen KN, Wang G, Cao LG, Zhang MC (2009) Differences of percutaneous retrograde screw fixation of anterior column acetabular fractures between male and female: a study of 164 virtual three-dimensional models. Injury, 40(10): p.1067-1072.

12. Trikha V, Kumar A, Mittal S, Passey J, Gaba S, Kumar A (2020) Morphometric analysis of the anterior column of the acetabulum and safety of intramedullary screw fixation for its fractures in Indian population: a preliminary report. Int Orthop, 44(4): p.655664.

13. Gänsslen A, Krettek C (2006) Retrograde transpubic screw fixation of transpubic instabilities. Oper Orthop Traumatol, 18(4): p.330-340.

14. Luksameearunothai K, Amin RM, Shafiq B, Hasenboehler EA (2020) Distance Between Reproductive Structures and the Insertion Point of the Retrograde Transpubic screw. J Orthop Trauma, 34(11): p.578-582.

15. Starr AJ, Nakatani T, Reinert CM, Cederberg K (2008) Superior pubic ramus fractures fixed with percutaneous screws: what predicts fixation failure?. J Orthop Trauma, 22(2): p.81-87.

16. Wu C, Deng J, Pan J, Li T, Tan L, Yuan D (2020) Anatomical conditions and patient-specific locked navigation templates for transverse sacroiliac screw placement: a retrospective study. J Orthop Surg Res, 15(1): p.260.

17. Schep NWL, Haverlag R, Van Vugt AB (2004) Computer-Assisted versus Conventional Surgery for Insertion of 96 Cannulated IS Screws in Patients with Postpartum Pelvic Pain. J Trauma Acute Care, 57: p.1299-1302.

18. Matta JM, Saucedo T (1989) Internal Fixation of Pelvic Ring Fractures. Clin Orthop Related R, 242: p.83-97.

19. Gänsslen A, Krettek C (2006) Retrograde transpubic screw fixation of transpubic instabilities. Oper Orthop Traumatol, 18(4): p.330-340.

20. Routt ML Jr, Simonian PT, Grujic L (1995) The retrograde medullary superior transpubic screw for the treatment of anterior pelvic ring disruptions: a new technique. J Orthop Trauma, 9(1): p.35-44.

21. Luksameearunothai K, Amin RM, Shafiq B, Hasenboehler EA (2020) Distance Between Reproductive Structures and the Insertion Point of the Retrograde Transpubic screw. J Orthop Trauma, 34(11): p.578-582.

22. Chen KN, Wang G, Cao LG, Zhang MC (2009) Differences of percutaneous retrograde screw fixation of anterior column acetabular fractures between male and female: a study of 164 virtual three-dimensional models. Injury, 40(10): p.1067-1072.

23. Ochs BG, Stuby FM, Ateschrang A, Stoeckle U, Gonser CE (2014) Retrograde lag screw placement in anterior acetabular column with regard to the anterior pelvic plane and midsagittal plane - virtual mapping of 260 three-dimensional hemipelvises for quantitative anatomic analysis. Injury, 45(10): p.1590-1598. 
24. Zhang LH, Zhang LC, Si QH (2016) Experimental study on treatment of acetabular anterior column fractures: applyment of a minimally invasive percutaneous lag screw navigation apparatus. BMC Musculoskelet Disord, 17: p.27.

25. Starr AJ, Nakatani T, Reinert CM, Cederberg K (2008) Superior pubic ramus fractures fixed with percutaneous screws: what predicts fixation failure?. J Orthop Trauma, 22(2): p.81-87.

26. Peng Y, Zhang L, Min W, Tang P (2016) Comparison of anterograde versus retrograde percutaneous screw fixation of anterior column acetabular fractures. Int J Comput Assist Radiol Surg, 11(4): p.635-639.

27. Giudice JS, Poulard D, Nie B, Wu T, Panzer MB (2018) A Cortical Thickness Mapping Method for the Coxal Bone Using Morphing. Front Bioeng Biotechnol, 6: p.149.

28. Osterhoff G, Wulsten D, Babu S, Heyland M, Pari C (2021) Antegrade versus retrograde screw fixation of anterior column acetabular fractures: a biomechanical in vitro study. Eur J Trauma Emerg Surg, 47(5): p.1307-1312.

29. Gras F, Marintschev I, Schwarz CE, Hofmann GO, Pohlemann T, Culemann U (2012) Screw-versus plate-fixation strength of acetabular anterior column fractures: a biomechanical study. J Trauma Acute Care Surg, 72(6): p.1664-1670.

30. Acker A, Perry ZH, Blum S, Shaked G, Korngreen A (2018) Immediate percutaneous sacroiliac screw insertion for unstable pelvic fractures: is it safe enough?. Eur J Trauma Emerg Surg, 44(2): p.163-169.

31. Frank M, Dedek T, Trlica J, Folvarský J (2010) Perkutánní osteosyntéza predního pilíre acetabula: první zkusenosti [Percutaneous fixation of anterior column acetabular fractures-first experience]. Acta Chir Orthop Traumatol Cech, 77(2): p.99-104.

\section{Tables}

Table 1 General information of patients

\begin{tabular}{|c|c|c|c|c|c|c|c|}
\hline \multirow[t]{2}{*}{ No. } & \multirow[t]{2}{*}{ Gender } & \multirow[t]{2}{*}{$\begin{array}{l}\text { Age } \\
\text { (years) }\end{array}$} & \multirow[t]{2}{*}{$\begin{array}{l}\text { BMI(Body Mass } \\
\text { Index) }\end{array}$} & \multirow[t]{2}{*}{$\begin{array}{l}\text { Tile } \\
\text { classification }\end{array}$} & \multicolumn{2}{|c|}{$\begin{array}{l}\text { Area of public } \\
\text { fracture }\end{array}$} & \multirow[t]{2}{*}{$\begin{array}{l}\text { Type of posterior ring } \\
\text { damage }\end{array}$} \\
\hline & & & & & Left & Right & \\
\hline P1 & Female & 38 & 21.1 & B2 & - & प & sacroiliac dislocation \\
\hline P2 & Male & 42 & 21.2 & B2 & प & - & sacral fractures \\
\hline P3 & Male & 38 & 25.7 & B2 & प & - & sacral fractures \\
\hline P4 & Male & 59 & 23.8 & B2 & - & प & sacral fractures \\
\hline P5 & Male & 51 & 22.8 & $\mathrm{C} 1$ & प & ( & sacral fractures \\
\hline P6 & Female & 61 & 23.3 & $\mathrm{C} 1$ & प & - & sacroiliac dislocation \\
\hline P7 & Female & 65 & 23.8 & B2 & प & - & sacral fractures \\
\hline P8 & Female & 48 & 25.7 & B2 & प & प & sacral fractures \\
\hline P9 & Male & 21 & 20.8 & B2 & - & ? & sacral fractures \\
\hline Mean & & 47 & 23.13 & & & & \\
\hline SD & & 13.1 & 1.75 & & & & \\
\hline Min & & 21 & 20.8 & & & & \\
\hline Max & & 65 & 25.7 & & & & \\
\hline
\end{tabular}

Table 2 Anatomical parameters of the pubic for 50 adults 


\begin{tabular}{|c|c|c|c|c|c|c|c|c|}
\hline & \multicolumn{4}{|c|}{ left+right $₫ n=100 \rrbracket$} & \multicolumn{2}{|c|}{ Corridor $A \rrbracket n=50 \rrbracket$} & \multicolumn{2}{|c|}{ corridor $B \otimes n=50 \bigotimes$} \\
\hline & Corridor A & Corridor B & $\mathrm{T}$ & $P$ & right & left & right & left \\
\hline $\begin{array}{l}\text { Diameter } \\
(\mathrm{mm})\end{array}$ & $11.16 \pm 2.13$ & $8.54 \pm 1.52$ & 19.13 & 0.00 & $11.05 \pm 2.02$ & $11.26 \pm 2.08$ & $8.36 \pm 1.56$ & $8.71 \pm 1.48$ \\
\hline $\begin{array}{l}\text { length } \\
(\mathrm{mm}), \mathrm{D}\end{array}$ & $86.39 \pm 9.35$ & $117.05 \pm 5.91$ & -39.74 & 0.00 & $86.13 \pm 9.58$ & $86.65 \pm 9.22$ & $116.78 \pm 6.33$ & $117.31 \pm 5.52$ \\
\hline $\begin{array}{l}\text { surface } \\
\text { distance } \\
\text { from the } \\
\text { screw entry } \\
\text { point to the } \\
\text { posterior } \\
\text { superior } \\
\text { iliac } \\
\text { spine (mm), } \\
\text { SD1 }\end{array}$ & $109.31 \pm 11.06$ & $127.86 \pm 8.23$ & -20.49 & 0.00 & $108.84 \pm 11.10$ & $109.78 \pm 11.12$ & $127.86 \pm 8.11$ & $127.85 \pm 8.44$ \\
\hline $\begin{array}{l}\text { surface } \\
\text { distance } \\
\text { from the } \\
\text { screw entry } \\
\text { point to the } \\
\text { posterior } \\
\text { inferior iliac } \\
\text { spine (mm), } \\
\text { SD2 }\end{array}$ & $91.16 \pm 10.34$ & $106.92 \pm 7.91$ & -19.53 & 0.00 & $90.14 \pm 10.45$ & $92.17 \pm 10.22$ & $106.48 \pm 8.07$ & $107.36 \pm 7.81$ \\
\hline
\end{tabular}

Table 3 Clinical results of patients

\begin{tabular}{|c|c|c|c|c|c|c|c|c|c|}
\hline \multirow[t]{2}{*}{ No. } & \multirow{2}{*}{$\begin{array}{l}\text { Surgical time } \\
\text { Imin! }\end{array}$} & \multirow{2}{*}{$\begin{array}{l}\text { Blood loss } \\
\text { Imll }\end{array}$} & \multirow{2}{*}{$\begin{array}{l}\text { Incision length } \\
\text { [cm }\end{array}$} & \multirow{2}{*}{$\begin{array}{l}\text { Radiation } \\
\text { (times) }\end{array}$} & \multirow{2}{*}{$\begin{array}{l}\text { Matta } \\
\text { criteria }\end{array}$} & \multicolumn{4}{|c|}{ Grading score } \\
\hline & & & & & & $\begin{array}{l}\text { Pubic- } \\
\text { L }\end{array}$ & $\begin{array}{l}\text { Pubic- } \\
\text { R }\end{array}$ & s1 & S2 \\
\hline P1 & 100 & 100 & 12 & 18 & Good & - & 0 & 0 & 0 \\
\hline P2 & 90 & 150 & 12 & 16 & Excellent & 0 & - & 0 & 0 \\
\hline P3 & 110 & 150 & 15 & 16 & Good & 0 & - & 0 & 0 \\
\hline P4 & 100 & 120 & 12 & 10 & Excellent & - & 0 & 0 & 0 \\
\hline P5 & 160 & 250 & 22 & 22 & Good & 0 & 0 & 1 & 0 \\
\hline P6 & 90 & 100 & 9 & 20 & Excellent & 0 & - & 0 & 0 \\
\hline P7 & 80 & 100 & 9 & 18 & Excellent & 0 & - & 0 & 0 \\
\hline P8 & 140 & 200 & 22 & 25 & Good & 1 & 0 & 0 & 0 \\
\hline P9 & 100 & 100 & 13 & 16 & Excellent & - & 0 & 0 & 0 \\
\hline Mean & 108.75 & 141.11 & 14 & 17.89 & & & & & \\
\hline SD & 25.71 & 50.21 & 4.62 & 4.01 & & & & & \\
\hline Min & 80 & 100 & 9 & 10 & & & & & \\
\hline Max & 160 & 250 & 22 & 25 & & & & & \\
\hline
\end{tabular}

Figures 

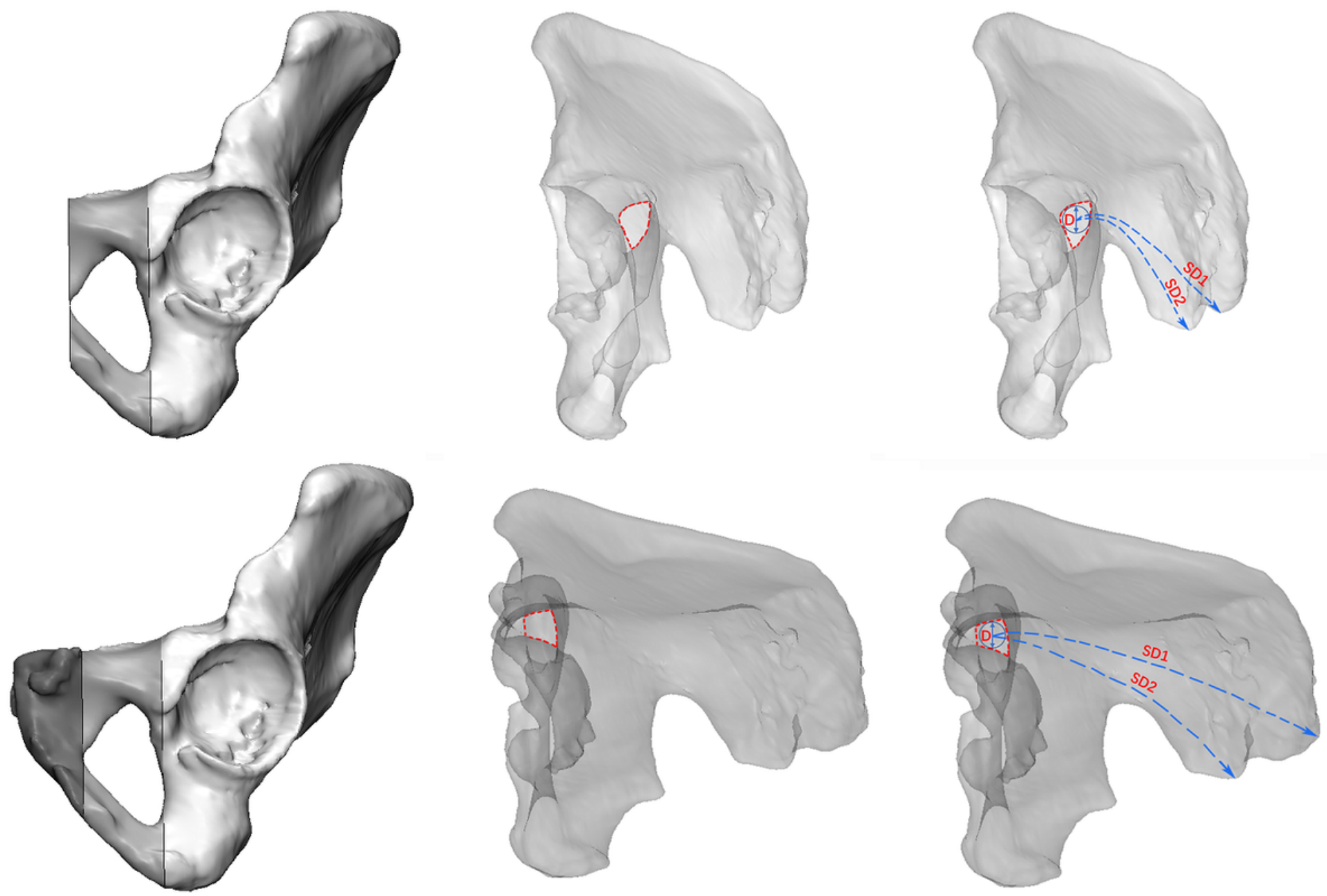

Figure 1

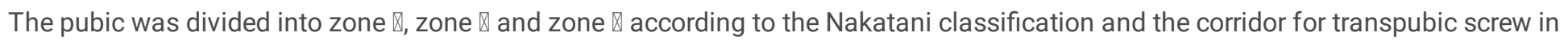
formed. A, B. the corridor A (an oval) was formed by the pubis of the zone $\nabla$ and $\Downarrow$. C. The diameter(D) of the tangent circle, length of the two corridors, distance along the lliac crest surface from the center of the tangent circle of the two channels to the posterior superior iliac spine (SD1) and to the posterior inferior iliac spine (SD2) was measured. D, E. the corridor A (a quadrilateral) was formed by the pubis of the zone $\otimes, \otimes$ and $\nabla$. $f$. The diameter(D) of the tangent circle, length of the two corridors, distance along the lliac crest surface from the center of the tangent circle of the two channels to the posterior superior iliac spine (SD1) and to the posterior inferior iliac spine (SD2) was measured.
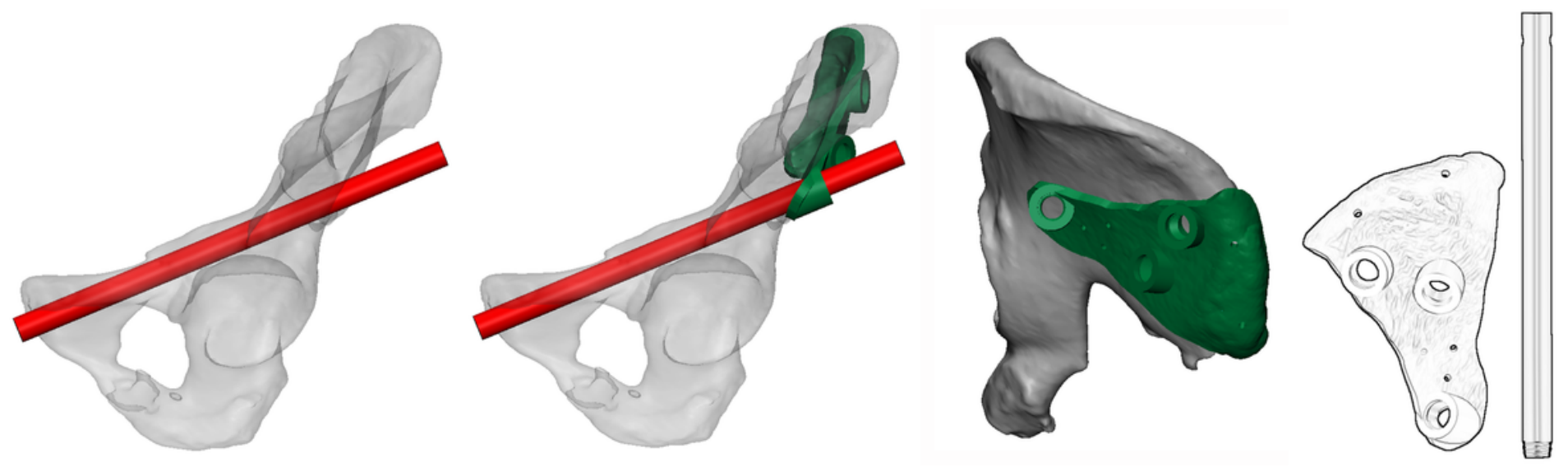

Figure 2 
The design of assembled navigation template. A, a virtual screw with diameter of $6.5 \mathrm{~mm}$ was inserted along corridor. B. The navigation base is designed with internal threaded holes in the direction of the virtual screw for assembly with the navigation pipe. C. The navigation base is designed with 5 holes of $2.7 \mathrm{~mm}$ for 2.5 screws to reinforce the attachment of the base to the iliac crest. D. Sketch of the assembled navigation template.

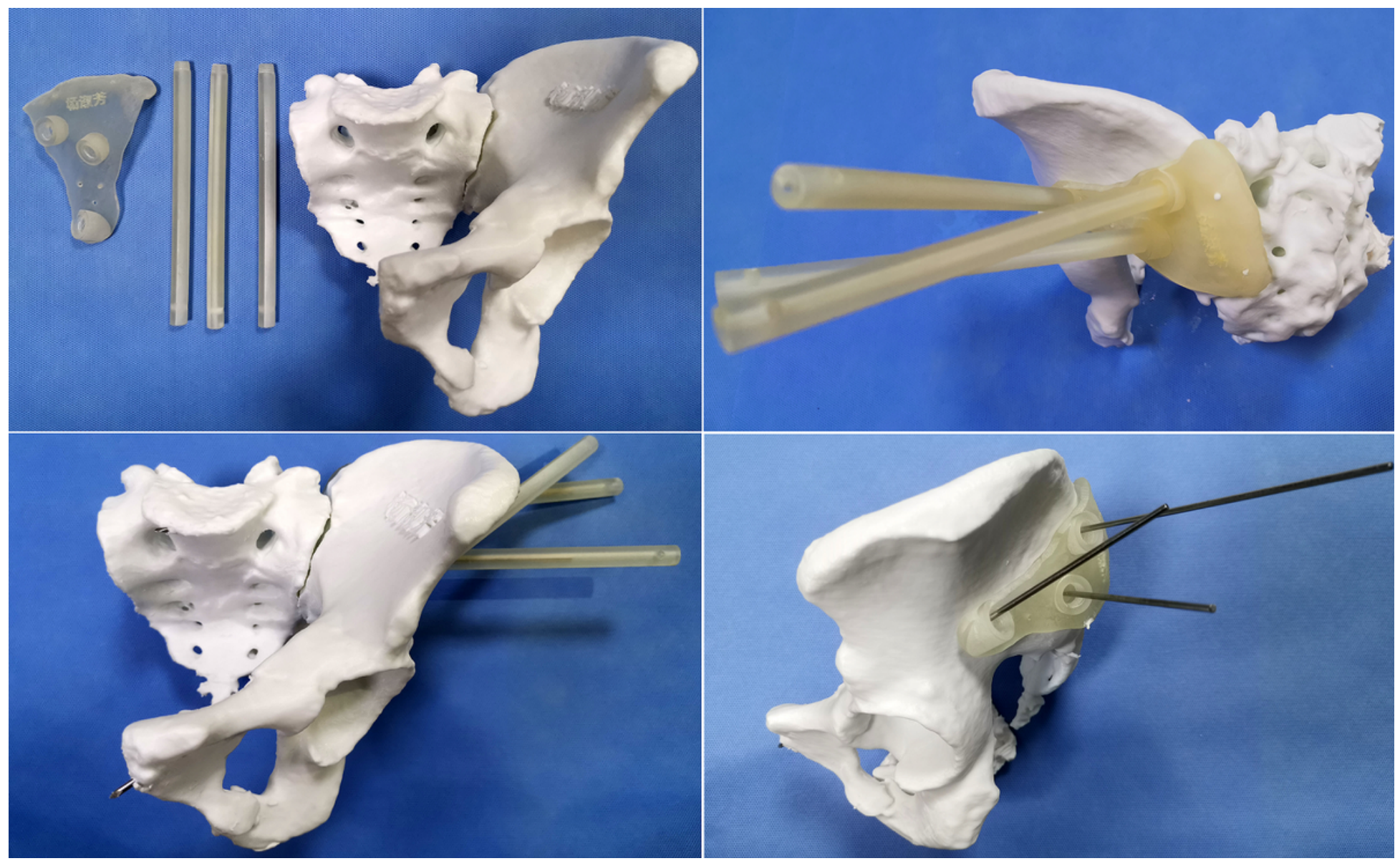

\section{Figure 3}

The transpubic screw placement simulation based on 3D printing. A. the 3D printed assembled navigation template and pelvic. B. The assembled navigation template was assembled and attached to the surface of the iliac crest. C, D. K wires were inserted under the assistant of a navigation template.
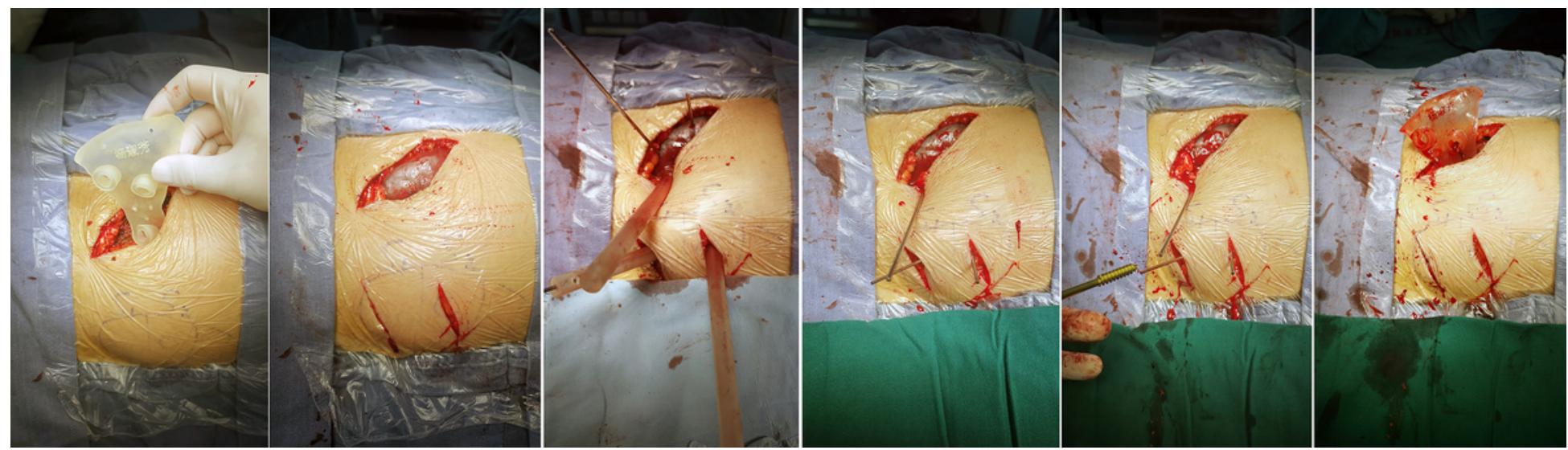

\section{Figure 4}

The operation procedure A. The template base was inserted through the incision on posterior superior iliac spine. B. The template base was completely attached to the corresponding target spot. C. navigation pipes were inserted and assembled with the navigation 
template base】and $\mathrm{K}$ wires were inserted along the navigation pipes. D. The $\mathrm{K}$ wires were inserted along the navigation pipes and navigation pipes were removed. E. The cannulated screws were inserted along the $\mathrm{K}$ wires. $\mathrm{F}$. The $\mathrm{K}$-wires and template base were removed

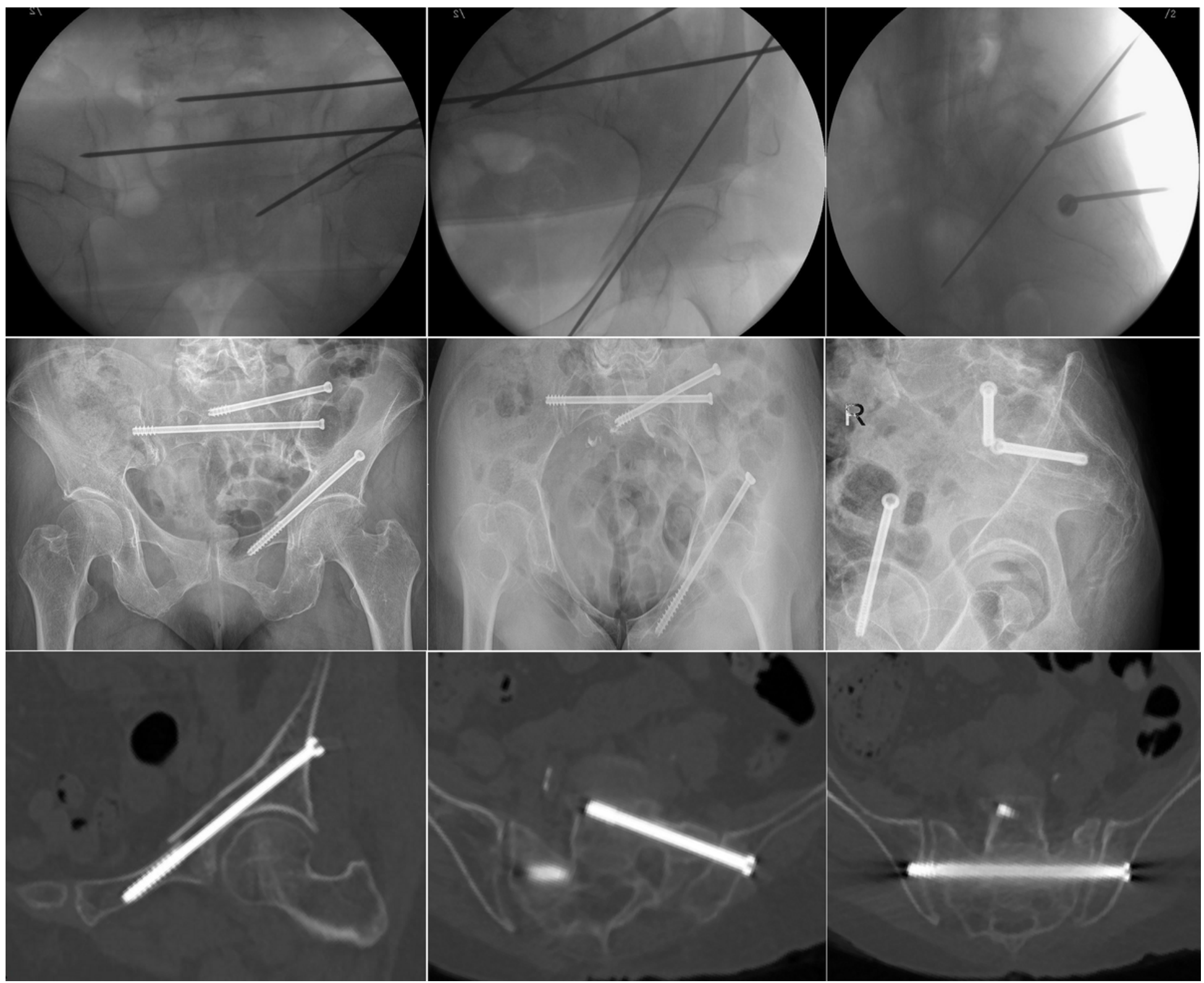

\section{Figure 5}

The radiological images of one patient. A-C. K-wires were inserted under assistance of the navigation template during the operation and $\mathrm{C}$-arm fluoroscopy confirmed none of the $\mathrm{K}$ wires breached the cortex. D. post-operation $\mathrm{X}$-ray of pelvic in outlet view. E postoperation X-ray of pelvic in inlet view. F post-operation X-ray of pelvic in lateral view. G, post-operation CT image of transpubic screw. $\mathrm{H}$, post-operation CT image of S1 screw. I. post-operation CT image of S2 screw. 